\title{
Cooperación y desarrollo en las comunidades locales de España y Perú
}

\author{
María Isabel Quevedo Alejos \\ Candidata a Doctora en Economía y Dirección de Empresas por la \\ Universidad de Deusto, San Sebastián, España. \\ Estudios de Maestría en Administración en la Universidad del Pacifico, Lima, Perú \\ Profesora e investigadora del Departamento Académico de Contabilidad de la \\ Universidad del Pacífico, Lima, Perú. \\ Quevedo_mia@up.edu.pe \\ Martha Chávez Passano \\ Candidata a Doctora en Economía y Dirección de Empresas por la \\ Universidad de Deusto, San Sebastián, España. \\ Estudios de Maestría en Administración en la Universidad del Pacifico, Lima, Perú \\ Profesora e investigadora del Departamento Académico de Contabilidad de la \\ Universidad del Pacífico, Lima, Perú. \\ chavez_ma@up.edu.pe
}

\section{Resumen}

En la actualidad, el mundo se enfrenta a un escenario de competencia creciente entre empresas y territorios. Los retos de la globalización obligan a las ciudades y las regiones a proponer estrategias que estimulen los procesos de acumulación de capital mediante la difusión de innovaciones y conocimiento, la adopción de formas más flexibles de organización de la producción y el desarrollo de economías de urbanización, entre otros factores.

Por ello, en este artículo analizaremos tres experiencias de desarrollo endógeno representadas por la Agencia Española de Desarrollo Iraurgi Lantzen (España), Finca Perú (organización civil peruana sin fines de lucro) y la Comunidad Campesina de Cullpe (Perú), con el fin de identificar y contrastar los diversos aspectos relacionados con el desarrollo autónomo de las comunidades.

La dinámica del proceso de desarrollo en cada región o ciudad se encuentra relacionada directamente con las decisiones de inversión y los atractivos de los que dependen los territorios. En el caso Iraurgi Lantzen se relata la mejora en la comarca ${ }^{1}$ del Urola Medio $^{2}$ con la construcción de una nueva carretera, lo que alienta a los municipios de la zona a buscar un consenso que los ayude a generar empleo y riqueza acorde con los intereses de fomento y promoción del valle. Por otro lado, el caso de Finca Perú nos muestra una iniciativa solidaria que

1. Comarca es la división del territorio que configuran varias poblaciones. El País Vasco tiene tres provincias: Álava, Guipúzcoa y Vizcaya, y dentro de cada una de ellas existen divisiones comarcales.

2. Urola Medio es una comarca que se encuentra ubicada en la provincia de Guipúzcoa y está constituida por los municipios de Azkoitia, Azpeitia, Beizama, Errezil y Zestoa. 
promueve el progreso y el desarrollo en las regiones más golpeadas por la pobreza y la subversión, como lo fueron las provincias de Huancavelica y Ayacucho, en la zona andina del Perú. Esta organización vela por la mejora socioeconómica de la población, particularmente mujeres, por medio de la creación del banco comunal, que actúa sobre la base de tres pilares fundamentales: desarrollo humano, crédito y ahorro. Finalmente, el caso de la Comunidad Campesina de Cullpe nos muestra un ejemplo de liderazgo social, innovación, capacidad de convocatoria y principios ético-morales que reaniman a una comunidad golpeada por la pobreza y limitada en recursos, creando ventajas comparativas y oportunidades para el desarrollo rural.

En conclusión, los casos analizados nos muestran que el desarrollo endógeno en las comunidades es posible olo si estas desarrollan una mayor capacidad para trabajar por una causa común identificada. De esa manera, se logra el beneficio del colectivo de una manera sostenible.

\section{Palabras clave}

Causa común, beneficio del colectivo, desarrollo endógeno, desarrollo humano, desarrollo sostenible

\section{Introducción}

En los últimos años, hemos visto cómo los sistemas productivos y los mercados adquieren de manera gradual una dimensión global; por lo que los temas de desarrollo local y descentralización han adquirido una relevancia creciente en muchos países.

Pérez Sáinz (2006) considera que los vínculos entre lo global y lo local identifican efectos potenciales contradictorios. Por un lado, la total marginación o la abstracción espacial y, por el otro lado, la revitalización de lo local, que puede generar o no desarrollo, dependiendo del tipo de inserción y del nivel de endogeneidad logrado.

Según Vázquez Barquero (2008), las ciudades y las regiones deben responder a los nuevos retos de la globalización mediante acciones que agilicen su dinámica económica, para así estimular los procesos de acumulación de capital, buscando un sendero duradero. La mejora de la productividad y competitividad de las comunidades depende de las innovaciones, la flexibilidad y la organización del sistema productivo, así como de la existencia de instituciones, que favorecen el desarrollo de las mismas.

En los países latinoamericanos, la problemática es totalmente diferente a la europea porque el proceso histórico de la población del continente respondió siempre a necesidades de los países desarrollados, desde la colonización española y portuguesa. En efecto, las ciudades se instalaron en función de las necesidades de los colonizadores, con los puertos como referentes básicos y generando espacios interiores con mínima densidad de población y, por ende, una actividad económica incipiente (González, 2002).

En el caso del Perú, desde la Colonia, el desarrollo político, social y económico se centró alrededor de la capital, Lima. Esto originó, más adelante, las grandes migraciones de pobladores del interior a la capital con la esperanza de encontrar mejoras, dejando de lado sus costumbres y su territorio. En la década de 1960, más del 60\% de la población limeña era migrante. Esta situación menoscabó la posibilidad de desarrollo local, por lo que fueron pocas las regiones que pudieron desarrollarse (Protzel 2001).

En el año 2002, en el Perú, se tomaron medidas para la descentralización regional. En esa dirección, se aprobó la Ley de Reforma Constitucional de Descentralización, instaurando las regiones bajo la lógica de la ubicación territorial, de tal manera que cada región se pueda desarrollar económica, social y culturalmente. Dicha descentralización recién se está implementando de manera efectiva y los beneficios se verán en el tiempo, en la medida que los 
intereses personales y políticos no se superpongan al desarrollo humano, social y económico de las regiones.

En los países de la Unión Europea (UE) se produjo un cambio en la estrategia de desarrollo local en las últimas tres décadas, pues se ha pasado de un enfoque concéntrico del desarrollo (modelo top down) a un enfoque endógeno o de abajoarriba (modelo bottom-up) (Sanchis 1999).

En España, a partir de la Constitución Española del año 1978, el Estado se organiza territorialmente en municipios, en provincias y comunidades autónomas. Todas estas entidades poseen autonomía para la gestión de sus respectivos intereses (Flores 2004).

La descentralización en España ha permitido que las comunidades autónomas deban ser más competitivas y productivas, para lo cual se han iniciado en el desarrollo local. Según ValcarcelResalt (citado en Sanchis 1999), en 1990 existían en España unas 258 experiencias de desarrollo local localizadas en regiones desarrolladas (Cataluña), regiones periféricas (Galicia y Andalucía), regiones dinámicas de desarrollo intermedio (Valencia) y regiones en declive industrial (País Vasco).

\section{Objetivo del estudio}

El propósito central del estudio presentado en este artículo ha sido entender cómo surgen los desarrollos locales de las comunidades en los países europeos y latinoamericanos, identificando los factores determinantes del éxito y tomando en cuenta el contexto en el que se desenvuelven.

\section{Marco conceptual}

Para poder entender cómo surgen estos desarrollos locales, partiremos de la definición de los conceptos básicos de desarrollo endógeno, humano y sostenible, planteados por diferentes autores, Saenz 1999, Vázquez Barquero 1999, Petrizzo et al. 2006, entre otros).

\section{Desarrollo endógeno}

Según Vázquez Barquero (1999), el desarrollo endógeno está referido al desarrollo desde adentro. El autor lo define como un modelo económico en el que las comunidades desarrollan sus propias propuestas. Es decir, la iniciativa parte de la comunidad, es el propio colectivo de los pobladores el que toma las decisiones.

Este enfoque de desarrollo busca la satisfacción de las necesidades básicas, la participación de la misma comunidad, la protección del ambiente, la localización de la comunidad en un espacio determinado. Asimismo, que los procesos locales y globales se complementen para lograr el desarrollo de la comunidad en el nivel local, y que luego trascienda a la economía del país y al mundo.

El desarrollo endógeno es un modelo económico en el que las personas de una comunidad se organizan, se comunican y suman esfuerzos por una causa común. En este contexto deciden compartir sus conocimientos para promover el progreso de su comunidad, utilizando sus recursos. Al organizarse, cada persona promueve también su propio progreso y, al mismo tiempo, se llega a un logro superior, pues se piensa en el beneficio colectivo.

Vázquez Barquero (1999) sostiene que en el ámbito local se detecta, por ejemplo, la dotación de una determinada estructura productiva, mercado de trabajo, capacidad empresarial, recursos naturales, estructura social y política, o tradición y cultura. Sobre ella puede articularse su crecimiento económico y la mejora del nivel de vida de la población.

El desarrollo endógeno se basa en el cambio del sistema productivo del país, para que cada región sea capaz de transformar sus recursos naturales en bienes y servicios que multipliquen el empleo y el bienestar social, lo que garantiza la calidad de vida para las personas y el medioambiente. 
Para Saenz (1999), las concepciones más recientes que definen el «desarrollo» se presentan en proyectos como desarrollo endógeno, desarrollo a escala humana, desarrollo sustentable y desarroIlo agropolitano. Estas propuestas se sustentan en el desarrollo iniciado en el nivel local, que es promovido por las fuerzas locales, es decir, «desde abajo».

El desarrollo agropolitano, planteado por Friedman y Weaver (citado en Saenz 1999), se basa en que «la capacidad de los pobladores para guiar las fuerzas de su propia evolución, descansa menos en la ayuda y en la inversión exterior; significa aprender a decir nosotros y a defender el interés territorial».

Boisier (citado en Saenz 1999) define el desarrollo endógeno como «el progreso permanente de la región, de la comunidad regional como un todo y de cada persona en ellas.

Según Vázquez Barquero (1999), el desarrollo endógeno busca ser inclusivo, es decir, incorporar a la población excluida, de tal manera que se adopten nuevos estilos de vida y de consumo. En ese sentido, el autor considera que intervienen diversos aspectos:

- La transformación de los recursos naturales.

- La construcción de cadenas productivas que enlacen producción-distribución y consumo.

- El aprovechamiento eficiente de la infraestructura.

- La incorporación de la población excluida.

- La adopción de nuevos estilos de vida y consumo.

- El desarrollo de nuevas formas de organización, tanto productiva como social.

- La construcción de microempresas y cooperativas.

- El respeto de las particularidades regionales y nacionales, potenciando sus propias fuerzas.

- El desarrollo de tecnologías alternativas.

- La transformación de recursos sin comprometer las generaciones futuras: productividad ecológica.
El desarrollo endógeno, por lo tanto, impulsa una economía social fundada en valores cooperativos y solidarios. En la economía social, el centro no es la ganancia, sino los hombres y las mujeres que la conforman. La economía social se basa en el desarrollo humano. Asimismo, con el desarrollo endógeno se desarrolla la autoestima y soberanía de los pueblos.

Por ello, Vásquez Barquero (1999) considera que el desarrollo endógeno es el proceso mediante el cual lo social se integra a lo económico, político y ecológico de la siguiente manera:

Integración económica: mediante la implantación de un sistema de producción específico. Este permite que los agentes locales (la comunidad) usen eficientemente los factores productivos y alcancen los niveles de productividad que los haga competitivos.

Integración sociocultural: entre los agentes económicos y sociales (comunidad que produce) y las instituciones locales, formando un sistema de relaciones que incorpora los valores de la sociedad al proceso de desarrollo.

Integración política: parte de abajo hacia arriba. Es decir, se logra mediante iniciativas de la comunidad y permite crear un entorno local que estimula la producción y favorece el desarrollo sostenible.

\section{Desarrollo humano}

Por lo antes expuesto, podemos decir que el desarrollo endógeno busca incorporar a la población excluida y adoptar nuevos estilos de vida y de consumo. Su objetivo consiste en impulsar una economía social que se base en valores cooperativos y solidarios. A su vez, la economía social se basa en el desarrollo humano, por lo que tiene como centro a los hombres y mujeres y no a la ganancia económica.

Entonces, debemos entender que el desarrollo humano es el proceso que permite ampliar las oportunidades de las personas, logrando así el desarrollo del país de una manera democrática y 
participativa (Vázquez Barquero 1999). Ello se ve reflejado, por ejemplo, cuando se da el acceso al ingreso y al empleo, a la educación y a la salud. Para ello, es necesario que todos tengan la oportunidad y libertad de participar en las decisiones comunitarias, disfrutando así de la libertad humana, económica, social y política.

Vázquez Barquero (2008) sostiene que Amartya Sen propone un cambio importante al exponer que el concepto de desarrollo va más allá del crecimiento y los niveles de la renta per cápita de un país o territorio, ya que estos son solo un instrumento para que las poblaciones realicen sus capacidades. Lo importante es que las personas lleven a cabo aquellas funciones y actividades que desean y son capaces de realizar. Por lo tanto, el desarrollo económico se logra mediante la utilización de las capacidades que las personas han desarrollado gracias a los recursos materiales $y$ humanos, y a la cultura que posee el territorio.

Para Alonso (citado por Vázquez Barquero 2008), Sen presenta el desarrollo como un proceso abierto que se alimenta de las oportunidades y capacidades de las personas, las cuales se transforman a lo largo del proceso.

Así, Vázquez Barquero (2008) propone que el desarrollo humano es una interpretación que pone al hombre en el centro del desarrollo, ya que las transformaciones y los cambios de la economía y la sociedad se producen gracias a sus capacidades creativas y emprendedoras. Esta visión de desarrollo se sustenta en términos de un modelo de desarrollo culturalmente sostenible, que interpreta los cambios en la economía y la sociedad como un proceso abierto y continuo.

\section{Desarrollo humano y aprendizaje}

Según Petrizzo et al. (2006), el desarrollo endógeno busca vincular estrechamente a la sociedad con la noción de bienestar y con el modo de alcanzarlo. Existe una preocupación, por parte de ella, por desarrollar toda su capacidad para lograr el bienestar.
Por lo tanto, el paradigma del crecimiento endógeno debe ir acompañado del paradigma del aprendizaje. Es decir, un proceso de enriquecimiento de la sociedad donde este desarrollo se inserte, mediante la incorporación y reforzamiento de vínculos entre los nuevos actores, así como de formas de aprovechamiento de los recursos naturales que garanticen su uso apropiado, permitiendo de esta manera el desarrollo de tecnologías sustentables para la sociedad y el espacio geográfico que esta ocupa.

Los vínculos sociales, entonces, son formas de consolidar las redes complejas de interacción, que trascienden los espacios de conocimiento e intervención propios de la revolución industrial y del discurso contemporáneo sobre el desarrollo.

Petrizzo et al. (2006) entienden que el nuevo paradigma pudiera definirse como un paradigma de aprendizaje, que posee un conjunto de atributos, entre los que se pueden identificar los siguientes:

- La aparición de formas de vinculación social comunicativas de carácter corporativo.

- La vinculación de las formas de aprendizaje a contextos funcionales que se acercan al modo cotidiano de vivir en el mundo.

- Una concepción de la sociedad que reconoce su condición de riesgo, es decir, aquella que procura la revisión critica reflexiva sobre el avance sostenido de la ciencia y la tecnología con énfasis en los efectos colaterales nocivos.

Señalan, asimismo, que «aun cuando es demasiado prematuro para que estos elementos se hayan consolidado en una forma determinada, es posible afirmar que la transición de la sociedad a nuevos paradigmas para orientar sus acciones [...] debiera tener como factor clave los procesos de aprendizaje que permitan la definición de nuevos proyectos y horizontes, a partir del reconocimiento del carácter contingente de lo alcanzado hasta ahora» (Petrizzo et al. 2006: 124). Este carácter contingente no se limita a espacios confinados de 
entrenamiento científico, tecnológico y disciplinario, sino que, además, se postulan interrogantes sobre principios de ordenamiento social, de vinculación entre las personas, racionalidad del intercambio entre individuos $\mathrm{y}$, finalmente, de los modos de asumir las propias disciplinas y su dominio en el proceso de evaluar el desempeño de la sociedad.

\section{Redes de aprendizaje}

Petrizzo et al. (2006) sostienen que una red de aprendizaje lleva a pensar en un espacio compartido por un conjunto de individuos, el cual favorece un aprendizaje conjunto mediante el uso de herramientas que ayudan a la interacción.

De acuerdo con este modelo de aprendizaje descrito, existen tres pilares fundamentales: la cooperación, la interactividad y la interdependencia, que pueden lograrse por medio de actividades conjuntas realizadas de forma presencial, por intercambios vía electrónica o una mezcla de ambas. Sin embargo, lo más importante para que una red de aprendizaje funcione es la necesidad de lograr que los miembros que la conforman tengan una misma visión, sin perder de vista el objetivo de la red, o bien la comprensión y el respeto hacia los puntos de vista de todos los miembros.

Los mismos autores refieren, asimismo, que las redes de aprendizaje tienen tres implicaciones directas. La primera, es la recontextualización del aprendizaje con un referente de comunidad y no de individuo, lo que permitirá la adquisición de un conocimiento compartido, en beneficio del grupo, más allá de la esfera individual. Este tipo de red de aprendizaje ayuda al crecimiento de la comunidad.

La segunda implicación está relacionada con la inclusión social. La generación de esta nueva forma de aprendizaje, en donde existe el debate, el intercambio y el encuentro, puede ser atractiva para sectores sociales excluidos del sistema educativo formal. Inclusive, abre la posibilidad de que sean estos sectores los que se encarguen de difundir la información generada y adquirida en el marco de la red, funcionando de esta forma como agentes multiplicadores de primer orden.

En tercer lugar, las redes de aprendizaje permiten adecuarse a contextos funcionales cotidianos, desarrollando al interior de la comunidad los diversos mecanismos de aprendizaje, que resultan de las formas en que la propia comunidad han ido construyendo su cotidianidad. Esto permite no solo lograr el enriquecimiento de las redes de aprendizaje, sino modos innovadores de apropiación de conocimiento, más complejos que las formas de aprendizaje tradicional.

Coincidiendo con los autores referidos en este tema, las redes de aprendizaje permiten abordar diversos temas de interés al interior de una comunidad, que al ser compartidos por sus miembros, por modos tradicionales o innovadores, logran construir un conocimiento compartido que tiene como objetivo generar una oportunidad de crecimiento para dicha comunidad.

\section{Desarrollo sostenible}

Para Vázquez Barquero (1999) es importante que las comunidades alcancen un desarrollo sostenible, ya que este satisface las necesidades del presente, sin menoscabar las capacidades de las futuras generaciones para satisfacer sus propias necesidades. Es decir, se trata de la renovación de los recursos en el tiempo y la reutilización de estos por generaciones futuras.

Son varios los aspectos o ámbitos que forman parte del desarrollo sostenible. Entre ellos, tenemos: la dimensión humana y la preocupación ambiental, el respeto por el medioambiente, la necesidad de lograr equilibrio entre el desarrollo y la preservación de la calidad de la vida y de los recursos naturales. Por ello, el desarrollo está relacionado con la cultura de cada pueblo, que se diferencia de acuerdo con las características de los diversos grupos étnicos y culturales. Por otro lado, el desarrollo sostenible implica el derecho de todo ser humano y de todos los pueblos a una existencia 
digna en un medioambiente sano. Finalmente, esto permite elevar la calidad de vida y el bienestar de toda la comunidad.

\section{Desarrollo endógeno, humano y sostenible}

Vázquez Barquero (1999) sostiene que el concepto que agrupa estos tres ámbitos, endógeno, humano y sostenible, comprende los derechos humanos fundamentales como principal objetivo, de manera que se tome al ser humano en su totalidad. Por otro lado, busca que los seres humanos se capaciten en:

- Alcanzar el desarrollo personal y comunitario.

- Transformar sus propios recursos para producir fuentes de empleo.

- Interactuar con la naturaleza y la tecnología.

- Preservar el medioambiente y aprovecharlo correctamente.

- Desarrollar sus regiones

- Elevar la calidad de vida.

Otro aspecto importante es que con el desarrollo endógeno también se desarrolla la autoestima, la soberanía y la dignidad de los pueblos. El desarrollo endógeno, visto como un sistema económico alternativo, exige a cada ciudadano asumir la transformación cultural, ser copartícipe y responsable de la calidad de vida. Esto pasa por asumir compromisos para alcanzar un desarrollo sostenible.

\section{Territorio}

En este contexto del desarrollo endógeno, el territorio tiene un peso importante, ya que sobre la base de él se lograrán esfuerzos comunes, desarrollo y sostenibilidad (Vázquez Barquero 1999). Es necesario analizar cuáles son los aspectos que están presentes en la economía, en lo social, en lo cultural, en el grupo humano, para explicar en qué medida un territorio es más o menos productivo que otro.

En este sentido, Reilly (citado por Saenz 1999) se refiere a que ciertos espacios informales que el gobierno ha dejado desatendidos, han sido ocupados por las ONG, comunidades de base, asociaciones populares y otros movimientos sociales a los cuales denomina «vasos capilares» de la sociedad civil, porque son el punto en el cual se produce el intercambio de recursos financieros, de información, de exigencias y de apoyo, que mantienen la salud de la democracia.

Es fundamental relacionar a estos elementos, administrativos y sociales, con el elemento espacial. Es así que el territorio cobra importancia, pues la gente vive, trabaja y se relaciona en un lugar determinado; es el plano local donde la participación comunitaria alcanza su máxima expresión, ya que los ciudadanos no son espectadores pasivos de los problemas y necesidades en común, sino que reaccionan ante estas situaciones en forma colectiva. La comunidad asume el papel protagónico en defensa de sus intereses.

Vázquez Barquero (1999) afirma que la disponibilidad y calidad de los recursos humanos son factores clave para el desarrollo de una localidad o región, ya que tienen una fuerte repercusión en la productividad del sistema empresarial, la competitividad territorial y el modelo cultural sobre el que se edifica el proceso del cambio y crecimiento económico. En este contexto, los recursos humanos calificados se convierten en activos estratégicos para lograr mejoras en la competitividad territorial.

\section{Metodología del estudio empírico}

El estudio empírico llevado a cabo ha sido realizado sobre la base de fuentes secundarias y está orientado a la comparación cualitativa de tres experiencias con perfiles diferentes. Una de ellas se sitúa en el País Vasco, España, y las otras dos en Ayacucho y Huancavelica, en el Perú.

El País Vasco o Euskadi es una de las comunidades autónomas situada en el noroeste de España. Entre los años 1990-2005 su economía creció significativamente, pasó de un PIB per cápita del $89,6 \%$ de la media de la UE a uno de $125,6 \%$ de la media en 2005 , lo que le situó entre los tres 
países con mayor renta en términos de poder de compra de la $\mathrm{UE}^{3}$. «Una de las causas de esta fortaleza económica se encuentra en el gran peso que tiene la industria y la construcción [en el País Vasco], que supone el $38,18 \%$ del PIB, mientras la media de los países de la UE alcanza el $26,41 \%$. [Esto] ha permitido que la industria vasca sea competitiva y gane participación en los mercados exteriores, especialmente en el europeo» ${ }^{4}$.

La política industrial, los incentivos a la inversión y el apoyo a la mejora de la calidad, la innovación y la tecnología llevado adelante por el Gobierno vasco han permitido alcanzar las actuales cuotas de competitividad, a lo que hay que sumarle el desarrollo del sector de servicios (que supone el $60,80 \%$ del PIB $)^{5}$.

El Perú, país de América del Sur, se encuentra en la primera parte del proceso de descentralización. Geográficamente, se divide en departamentos, constituyendo Ayacucho y Huancavelica dos de ellos. Asimismo, es importante mencionar que además cuenta con tres regiones naturales: costa, sierra y selva.

Es un país en desarrollo en el que, en el año 2007, el 39,3\% de la población se encontraba en situación de pobreza (en 2005, el 48,7\%) y el $13,7 \%$ en extrema pobreza (en 2005, el 17,4\%). Estas cifras varían significativamente entre la capital y el resto del país, entre las áreas rural y urbana, y entre dominios geográficos y región natural. Así, en la sierra, región donde se encuentran ubicados Ayacucho y Huancavelica, existe una alta incidencia de pobreza extrema: el 29,3\% de su población es pobre extremo; mientras que en la selva, esta cifra llega al 17,8\%. En ambos casos, el porcentaje se sitúa por encima del registrado en la costa (2,0\%). En el nivel departamental, Huancavelica cuenta con una inci- dencia de pobreza del $85,7 \%$ y Ayacucho, del 68,3\% (INEI 2008).

La economía de Huancavelica está centrada en la minería; mientras que en Ayacucho, las condiciones naturales del departamento no favorecen el desarrollo de la economía.

Ante estas dos realidades descritas con perfiles totalmente diferentes, nos permitimos mostrar tres casos, pertenecientes a estas regiones, en los que se ha podido lograr un desarrollo local con éxito. Por un lado, la realidad del País Vasco, que cuenta con las condiciones necesarias para lograr un alto nivel de competitividad y desarrollo, representando una de las regiones más desarrolladas de España; mientras que, por el otro, Huancavelica y Ayacucho, son dos departamentos del Perú con alta incidencia de pobreza y de violencia en la época del terrorismo. Estos últimos aspectos no favorecieron el desarrollo de una economía, generaron retraso y no permitieron que la población de estas zonas alcanzara un nivel aceptable de vida.

En este contexto, el primer caso analizado se sitúa en España y es liderado por la Agencia Española de Desarrollo Iraurgi Lantzen, que contribuye al desarrollo de la comarca de Urola Medio y los dos municipios que la componen: Azkoitia y Azpeitia, fomentando y promoviendo el valle de Urola Medio en el País Vasco. Los otros dos casos se ubican en el Perú; el primero, es el caso de Finca Perú, una organización sin fines de lucro que opera en las regiones de Ayacucho, Huancavelica y Lima, apoyando a las mujeres en desventaja económica y social, mediante la formación de fondos comunales y servicios de capacitación que facilitan el desarrollo integral de sus capacidades humanas. El segundo, es el caso de la comunidad campesina

\footnotetext{
3. Véase<http://www.turismoa.euskadi.net/s11-15733/es/contenidos/informacion/s11_acerca_euskadi/es_s11/ euskadicifras.html>

4. Ibid.

5. Ibid.
} 
Cullpe, ubicada al sur de Lima, que, gracias a su buena organización social y a su cultura por el trabajo y por la solidaridad, logró solucionar su problema de escasez de agua mediante la construcción de una represa, que aprovecha el agua de un vaso natural que podía almacenar este elemento de la lluvia, en un promedio de 50 mil metros cúbicos.

\section{Modelo de desarrollo del País Vasco}

A finales de la década de 1980, en el territorio de la comunidad autónoma vasca surgen agencias de desarrollo para afrontar el cambio constante que se evidenciaba no solo en España, sino en el mundo entero. La internacionalización de las empresas, los avances en las comunicaciones y el comercio exterior, entre otros temas, son ámbitos en los que las comunidades y las regiones estaban llamadas a participar.

Por ello, motivados por la idea de la acción de desarrollo económico interno, surgen las agencias de desarrollo locales incentivadas por entes propios y agentes económicos, cuyos fines apuntan a favorecer la generación de riqueza y la cohesión, igualdad e integración social entre los municipios de la comarca. Esta generación de empleo y desarrollo social propicia la asimilación de las capacidades de las personas y la mejora de la calidad de vida.

En 1992 se crea Garapen, la Asociación de Agencias Vascas de Desarrollo, sirviendo de plataforma representativa de todas las entidades implicadas en el desarrollo local. La asociación Garapen, cuya jurisdicción comprende el País Vasco, lleva más de una década promocionando el empleo y el apoyo a las nuevas iniciativas y a las pequeñas empresas mediante capacitación continua y financiación privilegiada. Entre sus objetivos para lograr desarrollo común se encuentran:
- Apoyar la creación de nuevas agencias de desarrollo del País Vasco y consolidar las existentes.

- Generar foros de debate donde se analice la actuación de las agencias de desarrollo.

- Consolidar la labor que los ayuntamientos ${ }^{6}$ realizan por medio de las agencias de desarrollo para mejorar el contexto económico de las pyme o 'pequeña y mediana empresa', y para la creación de empleo en el ámbito local".

\section{Modelo de desarrollo peruano}

Una de las principales conclusiones en el análisis del desarrollo económico local en América Latina es el carácter incipiente y el número reducido de mejoras de desarrollo existentes en la región. La mayoría de iniciativas de desarrollo han surgido como reacción a las crisis económicas y a la política inapropiada por parte del Estado.

El Perú, a principios de la década de 1980, sufrió uno de los momentos más críticos en su historia republicana. El surgimiento de la subversión y terrorismo, la violencia política, la crisis económica, la inflación descontrolada y la falta de empleo, acentuaron, aún más, este panorama sombrío para la nación. A estas limitaciones se une la centralización en la capital, Lima, del sector industrial y de la población que emigró a la costa en el apogeo del terrorismo. Este fenómeno puso en evidencia el elevado grado de desigualdad en la distribución del ingreso nacional.

En este período surgen las estrategias de supervivencia por parte de los pobres, promovidas por ellos mismos o por organizaciones populares, como los comedores populares, los clubes de madres y El Vaso de Leche. Las vinculaciones de los procesos de descentralización y las iniciativas de desarrollo económico local muestran que estos han surgido por la necesidad de adaptación ante la crisis económica.

6. Ayuntamiento es el órgano de administración de un municipio.

7. Véase <www.garapen.net>. 
Las experiencias estudiadas

\section{Caso Iraurgi Lantzen}

La comarca de Urola Medio se encuentra ubicada en el País Vasco, en la provincia de Guipuzcoa, en la pequeña cuenca del río Urola que la recorre de Sur a Norte. Se constituye por los municipios de Azkoitia, Azpeitia, Beizama, Errezil y Zestoa; y cuenta con una población de 28.000 habitantes.

Una característica central del panorama existente en el País Vasco es la baja densidad poblacional, sumada a problemas en la comunicación, lo cual pone a la comarca en desventaja frente al resto del continente. Las principales actividades que se realizan en Urola Medio son: agrícola-ganadera, industrial (madera y muebles de hogar, maquina-herramienta y siderurgia), construcción y el sector terciario (comercio, banca y servicios en general) ${ }^{8}$.

Como consecuencia de la cesión por parte de los ayuntamientos de ciertas funciones supramunicipales, en el año 1988, bajo la forma jurídica de sociedad anónima, y teniendo como objeto social la realización de cuantas actuaciones sean de interés para el fomento y promoción del Valle del Urola Medio y los municipios que lo componen, se constituyó la Sociedad de Urola Medio Iraurgi Lantzen.

Irarurgi Lantzen es la Agencia de Desarrollo de la Comarca de Urola Medio, integrada hoy por los municipios de Azkoitia y Azpeitia. Forma parte de la Asociación de Agencias de Desarrollo Garapen, con ámbito de actuación sobre los tres territorios de la Comunidad Autónoma Vasca.

La organización Iraurgi Lantzen presta servicios en los siguientes aspectos:
- Servicio de información y asesoramientos a empresas. Brinda una atención personalizada a las empresas de la comarca, colaborando con su gestión.

- Servicio de apoyo a nuevos emprendedores, tratando de promover y promocionar el autoempleo y nuevas iniciativas empresariales. Colabora en la realización de planes de negocio y estudios de viabilidad, búsqueda de financiación preferencial, seguimiento del negocio y otras actividades que transcurren parejas a la puesta en marcha de cualquier nueva empresa, tales como la elección de la forma jurídica, trámites por realizar.

- Dinamizar el sector comercial, mediante la reunión de todos los agentes implicados en el sector comercial, con el objetivo la mejorar la competitividad de las empresas comerciales de Azkoitia-Azpeitia.

Todas estas actividades tienen como objetivo generar un capital social capacitado, la creación de empleo, la promoción turística, la competitividad entre empresas y centros de investigación y un entorno propicio para el desarrollo de las actividades; demostrando que constituyen una herramienta útil a los fines perseguidos y un modelo de desarrollo ejemplar ${ }^{9}$.

Si bien en la actualidad la organización sigue operando a favor del servicio de dinamización empresarial, el pasado año 2008 fue uno atípico, en comparación con el histórico de años anteriores, al parecer influenciado por la actual coyuntura económica. Esta situación ha provocado la baja en la afluencia turística, el aplazamiento en la puesta en marcha de algunos proyectos e incluso la no disposición de financiamiento ajena a los proyectos presentados. A pesar de ello, en términos generales, la valoración del año realizada por Iraurgi Lantzen es positiva y, al parecer, el año 2009 es uno de transición, como consecuencia de la crisis mundial. 


\section{Caso Finca Perú ${ }^{10}$}

Finca Perú es una organización civil sin fines de lucro que opera en las regiones de Ayacucho, Huancavelica y Lima; las dos primeras ubicadas en la región de la sierra, presentan el mayor índice de pobreza y la mayor incidencia de la violencia terrorista; y la tercera, que es la capital, está ubicada en la región de la costa.

Esta organización se constituye con el fin de mejorar la situación económica de la población de escasos recursos, en particular de las mujeres, mediante la formación de fondos comunales y servicios de capacitación a grupos organizados en zonas urbano marginales y rurales del Perú.

En 1990, debido al terrorismo que se vivía, la mayoría de campesinos dejaron sus pueblos y emigraron a Huamanga, capital de Ayacucho. Sin embargo, al llegar encontraron una ciudad desprotegida, pues gran parte de la población había emigrado a la costa en búsqueda de seguridad.

Es en este contexto que Aquiles y Lucinda Lanao, de origen ayacuchano, vieron la oportunidad de crear los primeros bancos comunales como una manera de combatir la pobreza, por medio del servicio de desarrollo rural. Ellos siguieron la metodología diseñada por John Hatch (fundador de Finca internacional) y el 30 de julio de 1984, Aquiles Lanao Flores la formalizó en la cuidad de Nueva York, bajo el nombre de Fundación Internacional de Asistencia Comunitaria. Al cabo de dos años, ya contaban con 17 grupos organizados y con una cartera de aproximadamente US $\$ 20.000$. En 1993, estos bancos comunales fueron transferidos a Finca Perú que, afiliada a Finca Internacional y apoyada por otras organizaciones como Interamerican Foundation, Rotary Internacional, MSPIADEX-USAID, entre otras, inició sus operaciones en Huamanga, Ayacucho.
En 1994, en el Cono Sur y Este de Lima se inició un programa piloto para organizar bancos comunales, el cual creció y obligó a la creación de la Oficina Regional de Lima en 1997. En 1996, las operaciones se extendieron a Huancavelica, departamento catalogado como la zona más pobre del país, en donde se abrió una oficina regional. El programa de Finca Perú está diseñado para atender preferentemente a las mujeres, madres de familia, que tienen pequeños negocios y disposición para formar grupos solidarios ${ }^{11}$. La preferencia por las mujeres se basa en la hipótesis de que cuando las mujeres logran mayores ingresos, este beneficio llega directamente a toda la familia.

El instrumento que Finca Perú utiliza para poder cumplir con su misión es el banco comunal, que representa una metodología con tres pilares fundamentales complementarios, donde ninguno es más importante que el otro y, por otra parte, los dos no existen sin el tercero. Las actividades se desarrollan mediante reuniones semanales o quincenales de grupos de 20 a 25 mujeres, con el fin de realizar sus operaciones financieras y recibir capacitación.

Los tres pilares son:

- Desarrollo humano. Les proporcionan capacitaciones en temas de derechos y valores, salud; así como, en conocimientos técnicos (manejo del crédito) y en gestión empresarial para el mejoramiento del negocio. Esto les permite ser protagonistas de su propio desarrollo.

- Crédito. Implementar un sistema de crédito ágil, grupal, solidario, sostenible y de fácil alcance para las familias de escasos recursos, con el fin que puedan mejorar sus oportunidades de autoempleo y aumentar sus ingresos. El primer préstamo que proporciona

10. Elaborado sobre la base de Finca Perú 2002 y 2003.

11. Grupo de personas que cuenta con un pequeño negocio, para el cual reciben un crédito de manera grupal, y que se 
Finca Perú a cada una de las socias se denomina «capital semilla» y su origen es la denominada «cuenta externa». Este monto está fijado en US\$50 y aumenta de manera progresiva en los siguientes ciclos, en función de la solicitud y ahorro de cada socia, pudiendo llegar a US\$2.000. El período del préstamo es de 16 semanas (un ciclo) y la tasa de interés es de 3,5\% mensual. La forma de pago del préstamo es semanal e incluye capital, interés y ahorro programado. También se propicia que las socias evalúen y otorguen los llamados préstamos de la «cuenta interna». Los fondos de esta cuenta están formados por los ahorros programados y voluntarios de las socias, las amortizaciones semanales de la cuenta externa y los intereses. El préstamo es evaluado por la asamblea de socias en función del historial crediticio y del reglamento interno. Si el préstamo es superior a sus ahorros, este se otorga con la garantía de dos socias del banco comunal. El interés es de $3 \%$ mensual para el banco comunal, que se distribuye íntegramente entre las socias. Los préstamos pueden ser amortizados semanal o mensualmente.

Las garantías de los préstamos se fundamentan en la solidaridad y el apoyo social, se trata de propiciar el desarrollo integral de las socias.

- Ahorro. Finca Perú fomenta una cultura de ahorro que se basa en la disciplina, la perseverancia y el esfuerzo. Las socias deben cumplir con un ahorro programado, el cual deben traer a cada reunión, y el ahorro voluntario, que son montos por encima del programado y que representan montos que las socias quieren ahorrar en su banco comunal. Estos ahorros los manejan ellas mismas y están a su disposición en el momento que lo soliciten.

A las mujeres se les enseña que:

- El ahorro es la clave del crecimiento de ellas mismas y del banco comunal.
- El ahorro es un recurso que en el futuro formará un capital de trabajo propio.

- El ahorro es un recurso para enfrentar épocas de crisis en la familia.

- El ahorro sirve para la educación de los hijos.

- El ahorro es una palanca para recibir préstamos más grandes.

\section{Caso Comunidad Campesina de Cullpe ${ }^{12}$}

El centro poblado de Cullpe se ubica a $92 \mathrm{~km}$ al sur de Lima, capital del Perú, en la microcuenca del Camacha, que forma parte de la cabecera de la cuenca del río Turín. Políticamente pertenece al distrito de Tupicoche, provincia de Huarochiri, departamento de Lima.

Durante las últimas décadas, este espacio ha sufrido un fuerte y acelerado proceso de deterioro de su capacidad productiva agrícola y pecuaria, particularmente por la ruptura y alteración del ciclo hidrológico, la degradación de la cobertura vegetal, la erosión del suelo y la pérdida de su fertilidad. Esta problemática ambiental ha generado fuertes procesos de desertificación y reducción constante de la disponibilidad del agua, la deforestación creciente para leña y madera, así como el sobrepastoreo, que han contribuido de manera determinante a generar desequilibrios ecológicos en este espacio. Los servicios que brinda el Estado en educación y salud son de baja calidad y con recursos limitados, lo que no les permite tener una eficiente cobertura y contribuir a mejorar la calidad de vida de la población campesina.

Sin embargo, este espacio también ofrece ventajas comparativas y oportunidades para el desarrollo rural sustentable. Estas se explican en la cercanía a la capital, las prácticas de la agricultura tradicional, la buena organización comunal, la cultura al trabajo, la oferta turística y la alta biodiversidad del espacio geográfico.

12. Elaborado sobre la base de López y Hirbour (2001) y Centro de Investigación, Educación y Desarrollo (CIED). 
La comunidad campesina de Cullpe tiene a la producción agrícola como el sustento básico de su economía, siendo la actividad ganadera su complemento. En el sistema de producción coexisten la producción para el autoconsumo y la mercantil, la actividad agropecuaria está orientada a satisfacer principalmente las demandas del consumo familiar, es decir, garantizar la seguridad alimentaria; y los excedentes de la producción se articulan al mercado de Lima, observándose que en los últimos años esto último ha mostrado una tendencia creciente.

En este espacio se desarrolla una agricultura diversificada, con un alto componente de biodiversidad, que permite a los campesinos enfrentar en mejores condiciones los problemas fitosanitarios y de inestabilidad en los precios. Merece destacarse el conocimiento campesino en el manejo de los recursos naturales, en la captación del agua por medio de represas y reservorios, rotación y asociación de cultivos, empleo de abonos orgánicos, construcción de andenes y terrazas para evitar la erosión del suelo, reducir pendientes y regular los microclimas.

La tenencia de la tierra es, en promedio, una hectárea por familia. Este proceso de minifundio encarece los costos de producción y es un factor que presiona la migración de la población joven a la capital.

La escasez del recurso hídrico en la localidad de Cullpe es, tal vez, una de las razones para que los líderes se hayan interesado en buscar información y tecnologías que les permita hacer un uso más eficiente del agua.

En un inicio, la idea de construir y represar el agua de lluvia (denominada por algunos como «cosecha de agua») no contagió y animó a todos los comuneros. Sin embargo, la familia de los Rojas Melo, en una reunión comunal allá por el año de 1983, encomendó a seis de ellos el viaje al norte del país con la finalidad de conocer y observar el funcionamiento de las represas. Después de ese viaje, 16 de las 30 familias tomaron la decisión de construir la re- presa de Yanisiri sin ayuda externa. Bajo la dirección del hermano mayor, se diseña y realiza los cálculos económicos de la represa. Durante siete años, de 1983 a 1990, con sus aportes en dinero y trabajo, más la contratación de mano de obra asalaria$\mathrm{da}$, estas familias construyeron la represa.

El liderazgo alcanzado por esta comunidad se explica también por el número de familias que la componen: 30 familias, todas emparentadas entre sí. Las familias de los Rojas Melo y los Melo Rojas son las que más destacan por su organización, la cultura del trabajo, la solidaridad, sus innovaciones y sus habilidades para articularse al mercado de la capital. Ellos planifican y ejecutan, de manera coordinada, una serie de proyectos que les permite modificar la base productiva; así como, lograr niveles de productividad agrícola nunca antes alcanzados en la zona, tanto por el manejo agronómico como por la organización y participación en todo el proceso productivo.

A partir del año 1995, algunas organizaciones no gubernamentales (CIED y el Instituto de Desarrollo y Medio Ambiente-IDMA) e instituciones del Estado (Programa Nacional de Manejo de Cuencas Hidrográficas y Conservación de SuelosPRONAMACHS- y el Instituto Nacional de Innovación Agraria-INIA) se acercan a colaborar y fortalecer el proceso de desarrollo que habían alcanzado años atrás. El CIED Lurín se relaciona con esta comunidad en 1995. Para esa fecha, ya habían construido la represa de Yanisiri 1 y estaba funcionando el sistema de riego tecnificado en un promedio de 10 hectáreas, con cultivos de papa, arvejas y habas. Asimismo, empleaban estiércol para abonar sus cultivos, hacían rotación de cultivos, habían elevado la productividad de los mismos y la comunidad campesina se encontraba fortalecida y, sobre todo, muy bien prestigiada, no solo en su localidad sino en toda la cuenca del río Lurín. Es necesario reconocer que la muy elevada autoestima de los comuneros y sus capacidades de gestión, les permitieron entrar en una relación de igual a igual con los funcionarios del Estado y otras instituciones privadas de desarrollo. 
Después de haber logrado superar la escasez de agua, luego de haber logrado un importante capital humano y social, hoy, la comunidad campesina de Cullpe se enfrenta a nuevos desafíos que están relacionados con mejorar los sistemas de mercadeo agropecuario, diversificar su portafolio de cultivos, mejorar la productividad pecuaria y, principalmente, iniciar procesos de agroindustria rural con la finalidad de darle valor agregado a la producción local, en la estrategia de mejorar ingresos, y generar empleo.

Análisis de los factores del éxito en cada caso

Con el propósito de realizar un contraste entre los casos estudiados, analizaremos los factores que contribuyeron al éxito en el desarrollo local de las comunidades identificadas.

En caso Iraurgi Lantzen, a pesar de que han existidos momentos críticos desde el punto de vista político (expresado en la pugna entre los alcaldes) para poder realizar actividades conjunta entre los dos municipios, se pueden señalar los siguientes factores de éxito:

- La comunicación entre los dos municipios para impulsar el crecimiento y la riqueza de las comarcas.

- El consenso de acuerdo político.

- La visión del creador.

- La habilidad de los miembros de la agencia para tener una visión de futuro: adaptarse a las comarcas.

- La voluntad de los miembros de la comarca.

- La existencia de puntos comunes para desarrollar proyectos conjuntos.

- La confianza.

- El compromiso del personal que trabaja en la agencia.

Consideramos que, en el caso de Finca Perú, los factores de éxito fueron los siguientes:

- $\quad$ Su liderazgo visionario.
- Apostar por regiones olvidadas, no atractivas para ningún inversionista, afectadas por la vio- lencia terrorista.

- Creer en el poder de las personas, en sus capacidades y potencialidades, en la solidaridad y el trabajo en conjunto.

- Su capacidad de innovación, al tratar de adaptar la metodología de los bancos comunales a la realidad de las regiones más necesitadas de nuestro país.

- Contar con un personal comprometido e inmerso en los objetivos y valores de Finca Perú.

- La transparencia de sus actividades y en el manejo de su información, lo que le da credibilidad frente a sus clientas.

- Sus servicios enfocados a su clientela, puesto que combinan las mejores prácticas de microfinanzas con el desarrollo de capacidades para incrementar la autoestima y productividad de sus clientes.

- Fortalecer los valores humanos.

Asimismo, es importante mencionar que si bien son muchos los factores de éxito, en un inicio tuvieron algunos obstáculos, tales como la idiosincrasia de la población, la dependencia de la mujer del hombre, el machismo, la desconfianza, el idioma, puesto que en las zonas de Ayacucho y Huancavelica se habla más el quechua.

Por último, en el caso de la Comunidad Campesina de Cullpe, se pueden rescatar los siguientes factores del éxito:

- Importancia del capital humano.

- Desarrollo de conocimientos, tecnologías, actitudes y capacidades para articularse al mercado.

- Mejora de la negociación con los comerciantes.

- Capacidad para enfrentar las restricciones de los recursos naturales.

- Organización comunal con autoridad, legitimidad y capacidad de convocatoria.

- Líderes decisivos y comprometidos con su gente.

- Objetivos y metas claras por alcanzar, considerando las dimensiones sociales, económicas, ambientales y culturales. 
- Cultura de trabajo.

- Buena organización comunal.

- Capacidad para innovar y adoptar tecnologías.

- Respeto a sus experiencias y conocimientos de agricultura tradicional.

- Valores y principios éticos.

A continuación, mediante un cuadro comparativo (cuadro 1), evaluaremos el grado de cumplimiento de los factores del desarrollo endógeno (Vázquez Barquero 1999) en cada uno de los casos estudiados.

Del análisis realizado es posible observar que los casos estudiados cumplen con los factores que forman parte del desarrollo endógeno. Estas son organizaciones flexibles, creadas sin fines de lucro, que planifican y ejecutan proyectos con una agenda de trabajo clara y definida para mejorar la situación de su comunidad, con una visión compartida entre sus integrantes, mediante la capacitación de su capital humano en temas tales como finanzas, salud, comunicación y liderazgo, con la finalidad de lograr la promoción de pequeñas empresas o negocios que generen bienestar y progreso común.

\section{Conclusiones}

Es evidente que el desarrollo local y la descentralización contribuyen al desarrollo de las regiones y al crecimiento del país, ergo, del continente. Aunque se han desarrollado en contextos diversos, los casos presentan varios patrones comunes, tales como la voluntad de las personas, la solidaridad como valor fundamental de sus actores, el afán de progreso de estos colectivos y la lucha por una causa común.

En el caso de Iraurgi Lantzen es evidente un impulso en el crecimiento y las riquezas de la comarca, en vista del consenso desde el punto de vista político para poder realizar estas actividades. Se resalta la voluntad de los miembros de la comarca y los compromisos personales de las agencias de desarrollo.

Cuadro 1

Grado de cumplimiento de los factores del desarrollo endógeno en los casos estudiados

\begin{tabular}{|c|c|c|c|}
\hline \multirow[b]{2}{*}{ Factores del desarrollo endógeno } & \multicolumn{3}{|c|}{ Casos } \\
\hline & Irraugi Lantzen & Finca Perú & $\begin{array}{l}\text { Comunidad } \\
\text { Campesina Cullpe }\end{array}$ \\
\hline Se basa en sus capacidades y necesidades & Alto & Alto & Alto \\
\hline $\begin{array}{l}\text { Ubica territorialmente el esfuerzo en los } \\
\text { núcleos de desarrollo endógeno }\end{array}$ & Alto & Alto & Alto \\
\hline Motiva la participación de la comunidad & Alto & Alto & Alto \\
\hline $\begin{array}{l}\text { Estimula la repartición equitativa de la } \\
\text { riqueza }\end{array}$ & Alto & Medio & Medio \\
\hline Se organiza desde abajo hacia arriba & Alto & Alto & Alto \\
\hline $\begin{array}{l}\text { Reduce la exclusión social, garantizando } \\
\text { calidad de vida para todos }\end{array}$ & Alto & Medio & Medio \\
\hline $\begin{array}{l}\text { Promueve la adopción de nuevos estilos de } \\
\text { vida y consumo }\end{array}$ & Alto & Alto & Alto \\
\hline $\begin{array}{l}\text { Recompensa el trabajo productivo antes } \\
\text { que el afán de lucro }\end{array}$ & Alto & Medio & Medio \\
\hline $\begin{array}{l}\text { Utiliza las tecnologías apropiadas a la } \\
\text { región }\end{array}$ & Alto & Alto & Alto \\
\hline $\begin{array}{l}\text { Desarrolla todas las ramas de la economía } \\
\text { generando redes productivas }\end{array}$ & Alto & Alto & Alto \\
\hline
\end{tabular}

Elaboración propia 
En el caso de Finca Perú, a pesar de los problemas que pudo tener, no hay duda de que estos factores de éxito fueron importantes para que cumpla con su misión de contribuir a la autovaloración de mujeres empeñadas en superar las condiciones de pobreza en la que viven, así como de promover su creatividad y de facilitar el uso pleno de sus potencialidades. Esto, asimismo, ha permitido un cambio en miles de familias pertenecientes a las zonas de Ayacucho, Huancavelica y Lima, mejorando su calidad de vida.

Si bien Iraurgi Lantzen y Finca Perú operan en dos realidades muy diferentes, se han encontrado algunas similitudes en cuanto a los factores de éxitos en ambas organizaciones.

Entre algunos aspectos que se pueden tomar en cuenta para mejorar las actividades de Finca Perú tenemos: detectar otras necesidades de la población para financiar actividades que permitan un mayor desarrollo económico de las regiones; por ejemplo, préstamo para la agricultura, el desarrollo de cursos de alfabetización a las familias, promoción de proyectos conjuntos entre las clientas para lograr el desarrollo de actividades que tengan un mayor impacto en la zona y buscar apoyo financiero de instituciones privadas.

Finalmente, en cuanto al caso de la Comunidad Campesina de Cullpe, los resultados alcanzados parecieran deberse a la importancia que le han otorgado al capital humano, lo que les ha dotado de conocimientos, tecnologías, actitudes y capacidades para articularse al mercado, mejorar la negociación con los comerciantes, desarrollar capacidades para enfrentar las restricciones de los recursos naturales y en el fortalecimiento del capital social. Es decir, la organización comunal con autoridad, legitimidad y capacidad de convocatoria.
La comunidad campesina de Cullpe ha pasado de una economía de subsistencia con inseguridad alimentaria, a una economía mercantil con seguridad alimentaria. En la actualidad, tiene una economía diversificada que le permite superar no solo la fragilidad ambiental, sino también la económica.

Los casos analizados nos permiten llegar a la conclusión que se demuestra lo dicho por Vázquez Barquero respecto de que el desarrollo endógeno se centra en un modelo económico en el que las comunidades desarrollan sus propias propuestas, tal como se evidencia en caso de Iraurgi Lantzen, que encuentra el consenso para impulsar la economía de la región, resaltando la voluntad de sus miembros para lograrlo.

El mismo autor señala que se está frente a un desarrollo endógeno cuando las personas de una comunidad se organizan, se comunican y suman esfuerzos por una causa común; deciden compartir sus conocimientos para promover el progreso de su comunidad utilizando sus recursos. Esto se puede observar en los casos de Finca Perú y la Comunidad de Cullpe, en donde los pobladores han sumado esfuerzos para alcanzar un objetivo común que beneficie a sus pobladores y desarrolle su comunidad, ayudando a su crecimiento.

Una comunidad interesada en aprender de las experiencias de Iraurgi Lanzten, Finca Perú y Cullpe, debiera comenzar con la identificación de líderes dentro de su comunidad, que tengan legitimidad, autoridad y capacidad de convocatoria, y que generen confianza, pues todo ello permitirá que puedan organizar a los pobladores en alcanzar objetivos comunes. Se requieren líderes decisivos y comprometidos con su gente y con una causa común. 
Referencias

\section{EZAGUTZA GUNEA}

2003 Memoria anual 2003. Paçís Vasco: Ezagutza Gunea.

\section{FINCA PERÚ}

2003 Memoria anual 2003. Lima: Finca Perú.

2002 Memoria anual 2002. Lima: Finca Perú.

\section{FLORES, F.}

2004 «La descentralización en España y la autonomía política de los entes territoriales». En: WOISCHNIK, J. Anuario de derecho constitucional latinoamericano 2004. México D.F.: Fundación Konrad-Adenauer, pp. 429-437.

\section{GONZÁLEZ P., E.}

2002 El desarrollo local en Uruguay. Análisis y potencialidades. Serie Documentos de Trabajo del Rectorado, No 17 . Uruguay: Universidad de la República.

\section{GONZALO, A.}

1988 «Reflexiones sobre la economía del País Vasco». En: Revista Cuenta y Razón, № 33 (Ejemplar dedicado a: El País Vasco), pp. 53-58.

\section{INSTITUTO NACIONAL DE ESTADÍSTICA E INFOR-} MÁTICA-INEI

2008 Informe técnico: La pobreza en el Perú en el año 2007. Lima: INEI. <http:// censos.inei.gob.pe/documentosPublicos/ Informe_Tecnico_PobreZa2007.pdf>.

KARLAN, D.

2003 «Monitoring and Enforcement: Understanding Why Social Capital Generates Higher Repayment Rates». Northeast Universities Development Consortium Conference (NEUDC). New Haven, CT, octubre. <http:// www.econ.yale.edu/conference/neudc03/ papers/3d-karlan.pdf>.

\section{LÓPEZ, E. y C. HIRBOUR}

2001 Un caso exitoso de desarrollo endógeno: Comunidad Campesina de Cullpe. Lima: Centro de Investigación, Educación y Desarrollo (CIED)
LOWE, P.; J. MURDOCH y N. WARD

1997 «Redes en el desarrollo rural: más allá de los modelos exógenos y endógenos». En: Agricultura y Sociedad, No 82, pp. 13-43.

NOGALES, M. A.

2006 «Desarrollo rural y desarrollo sostenible. La sostenibilidad ética». En: CIRIEC-España. Revista de Economía Pública, Social y Cooperativa, №55, pp. 7-42.

PÉREZ SÁINZ, J.P.

2006 «Globalización y comunidad de vecindad. Notas para el planteamiento de un concepto». En: Iconos. Revista de Ciencias Sociales, No 24, pp. 27-42.

PETRIZZO, M.; A. OCHOA y E. ALDANA

2006 «Desarrollo endógeno y la necesidad de generar procesos de aprendizaje comunitario». En: OCHOA, Alejandro (ed.). Aprendiendo en torno al desarrollo endógeno. Mérida: Centro de Investigaciones en Sistemología Interpretativa (CSI), Consejo de Desarrollo Científico, Humanístico y Tecnológico (CDCHT), Fundacite-Merita, pp. 121-138.

PROTZEL, J.

2001 «Continuidades, hibridaciones y rupturas. Un ensayo sobre la interculturalidad del Perú». En: América Latina Hoy, № 28, pp. 149-169.

SAENZ, A.

1999 «Contribuciones al desarrollo endógeno: participación comunitaria, poder local, ONGs». En: Scripta Nova. Revista Electrónica de Geografía y Ciencias Sociales, vol. 3, № 45 (26).

SÁNCHEZ, J.

2006 «Los retos de lo local en lo global: aportes analíticos y normativos. Comentarios al dossier de Íconos 24». En: Iconos. Revista de Ciencias Sociales, № 25, pp. 77-88. r 
SANCHIS, J.R.

1999 «Las estrategias de desarrollo local: aproximación metodológica desde una perspectiva socioeconómica e integral». En: Revista Dirección y Organización-CEPADE, № 21, pp. 147-160.

VALDIVIA, M.

2004 Acerca de la dinámica de los bancos comunales y la sostenibilidad de las instituciones financieras que las promueven: aprendiendo de la experiencia de Finca-Perú. Lima, Perú: Grupo de Análisis para el Desarrollo (Grade).

VÁZQUEZ BARQUERO, A.

2008 «Desarrollo local: diversidad y complejidad de las estrategias y políticas de desarrollo». En: Prisma, № 22, pp. 35-58.

2005 Las nuevas fuerzas del desarrollo. Barcelona, España: Antoni Bosch editor.

2000 «Desarrollo endógeno y globalización». En: Eure, vol. 26, № 79, pp. 47-65.

1999 Desarrollo, redes e innovación. Lecciones sobre desarrollo endógeno. Madrid, España: Pirámide.

ZAPATA, EMMA; J. LÓPEZ, M. HERNÁNDEZ, L. GARZA, P. RAMÍREZ, M. RAMOS y C. REYES

2004 Microfinanciamiento y empoderamiento. México: Plaza y Valdés Editores.

\section{Páginas web}

ESPAÑA - PAÍS VASCO

Euskadi

http://www.turismoa.euskadi.net

Iraurgi Lantzen S.A.

http://www.iraurgilantzen.net/

Garapen-Asociación de Agencias Vascas de Desarrollo

http://www.garapen.net/

PERÚ

Centro de Investigación, Educación y Desarrollo (CIED)

http://www.ciedperu.org/ciedlima.htm

Finca Perú

http://www.fincaperu.net/ 